\title{
Analysis of methods to increase the efficiency of ship refrigeration plants
}

\author{
Igor Ovcharenko ${ }^{1}$, Valeriy Yenivatov ${ }^{1}$ and Alexei Vyngra ${ }^{1, *}$ \\ ${ }^{1}$ Kerch State Maritime Technological University, Department of ships propulsion plants, Kerch, \\ Russia
}

\begin{abstract}
The review of the applicable methods for increasing the efficiency of ship refrigeration plants is made. For the presented methods, such as refrigerant subcooling and automatic control of compressors in refrigeration plant, the expediency of application is discussed on the assumption of marine operational conditions and using R22 and R717 refrigerants.
\end{abstract}

\section{Introduction}

The increasing of efficiency of refrigeration plant operation can be reached by various methods: constructive improvement of elements, development and application of progressive automatic control systems, heat transfer enhancement, and thermodynamic enhancement [1]. In practice, many methods are connected with operation of small capacity refrigerating machines. For example, in a refrigeration plant of a fishing fleet, cooling systems influence the complex of thermodynamic processes and determine the efficient operation. During operation in special conditions, the requirements to the marine refrigeration plants are high efficiency, reliability and ecological safety. It is necessary to consider a number of features for practical application of the methods for increasing the efficiency.

Modern publications contain descriptions of methods of refrigeration plant efficiency, which allow determining the future prospects for its use in marine conditions in order to increase the energy efficiency of a reefer ship.

The purpose of present paper is to analyze possible ways to increase the efficiency of a reefer ship.

In publication [2], the refrigerant subcooling is described as method for increasing the thermodynamic effectiveness of a refrigeration plant. Subcooling of refrigerant is a complex thermodynamic process that is achieved by installation of the additional shell-and-tube heat exchanger between the condenser and the evaporator to increase the refrigerating capacity (Figure 1).

\footnotetext{
*Corresponding author: sergiiblack@mail.ru
} 


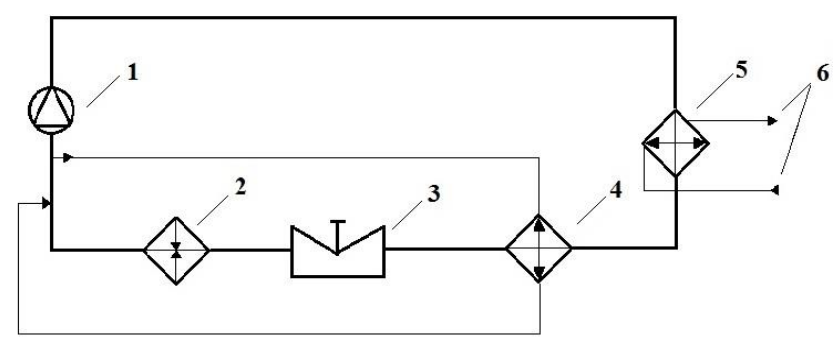

Fig. 1. Scheme of a refrigerator set with the additional heat exchanger, where: 1 - compressor; 2 evaporator; 3 - thermostatic expansion valve; 4 - additional heat exchanger; 5 - condenser; 6 supply and pipe-bend of a refrigerating liquid.

In Figure 1, subcooling of the liquid refrigerant going from the condenser (5) at condensation pressure to a thermostatic expansion valve (3) is cooling below condensing temperature. There are various ways of subcooling: due to boiling of refrigerant with the intermediate pressure, by expensed vaporous refrigerant going out of the evaporator and by heat transfer to outboard water. Subcooling of liquid refrigerant allows increasing refrigerating capacity of the refrigeration plants [3]. The operation time of the compressor is reduced at the same efficiency.

The installation of the additional heat exchanger(4) (Figure 1) allows decreasing the temperature of refrigerant due to the vapors going out of the evaporator and increasing the enthalpy in the refrigeration cycle (Figure 2). The main advantages of this method are increasing in thermodynamic effectiveness, subcooling of liquid refrigerant to prevent evaporation before a regulating valve, evaporation of a small amount of the liquid carried away from the evaporator. Various types of additional heat exchangers are applied: shelland-tube heat exchangers; heat exchanger "pipe in pipe" - the countercurrent subcooling, subcooling by refrigerant evaporation on the outer side of tubes [4].

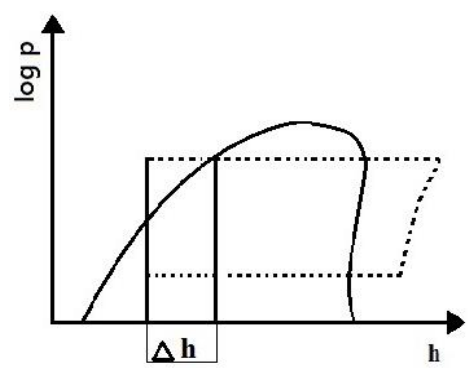

Fig. 2. Increase of the enthalpy caused by subcooling.

The shell-and-tube heat exchangers are used for small refrigeration plants with a refrigerating capacity less than $14 \mathrm{~kW}$. For refrigerators with higher refrigerating capacity, the application of heat exchangers of other types is required. The double-pipe heat exchangers are used for subcooling due to evaporating of liquid refrigerant at the intermediate pressure. It can be carried out in the intercoolers and economizers, which are applied in the two-stage compression refrigerators and are installed between compressors of the first and second steps. As well as the shell-and-tube heat exchanger, only refrigerators with a small refrigerating capacity are applicable.

During countercurrent subcooling of liquid refrigerant, the liquid flows outside the tubes in the countercurrent direction of the cooling external water flowing inside the internal tubes. One or two sections assembled in series include double pipes ("pipe in pipe"). Inner tubes are connected by special cast iron framings, external ones are welded. Due to its design characteristic, the subcooling of a liquid refrigerant by a refrigerant evaporating outside the 
pipes is considered more effective for the subcooling of refrigerants of various types and installations with different refrigerating capacity.

However, the lack of the scheme of regulation of subcooling limits a range of application of this method in ship refrigeration plants. Also, it is necessary to consider all operational modes of the refrigeration plants. Moreover, the refrigerant subcooling is not applicable at all working conditions of refrigeration plant, and the use of the considered heat exchange devices is impossible for real ship refrigeration plants.

In article [5], the task of increasing the performance efficiency of the refrigeration plants by improving evaporators is discussed. The installation of the flooded evaporator with the additional screens is proposed that allows improving thermodynamic processes and changing the refrigerant flow distributions. Using this method, the metal consumption is reduced by $38 \%$, and the heat transfer coefficient increases at average by $9 \%$ for $\mathrm{R} 717$ refrigerant. However, to create a flow distribution of the vapor-liquid mixture and the liquid refrigerant in the evaporator on the actual refrigeration plant, overdesign is required. So, all improvements proposed in paper [5], although partially experimental, are difficult for application in ship refrigeration plants. The proposed improvements use R717 refrigerant which has rigorous requirements for ecological safety. In this regard, it is necessary to consider a number of features given in normative standards $[6,7]$.

The temperature control algorithm for the expansion valve is presented in [5]. There are three ways to implement this solution: the mechanical thermostatic expansion valve (routine method); the electronic controlled expansion valve operated by an algorithm with the constant setting; the electronic controlled expansion valve operated by an algorithm of adaptive setting. Dependence of evaporation point on overheating size is taken as the basis for the scheme (Figure 3). The suggested three ways of control can find application in refrigeration plants of various types. In practice, in real ship refrigeration plants, it is necessary to consider a number of features connected with the design of elements that are a part of a system. The practical application is possible, but it requires the elaboration of automatic control systems and the installation of additional data-units to control thermodynamic processes.

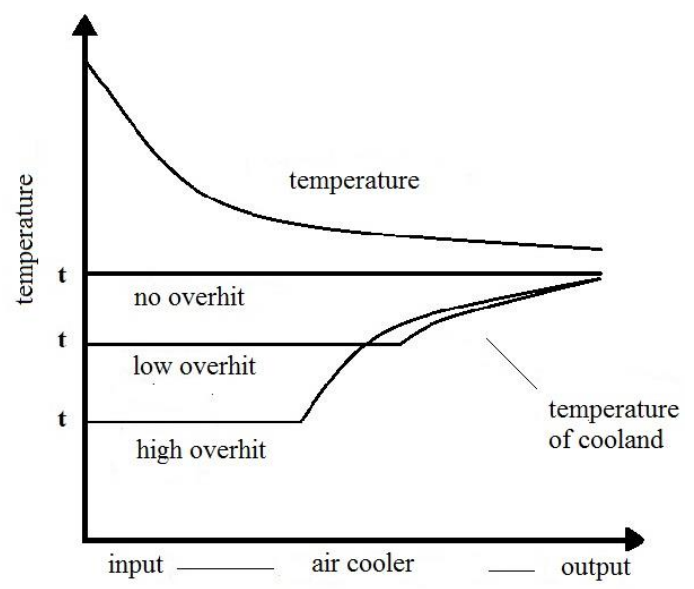

Fig. 3. Dependence of boiling point on overheating size.

As a solution for the problem of increasing the efficiency of real ship refrigeration plants, the application of the frequency converters for controlling the drives of compressors is possible for the low-temperature and medium-temperature cargo refrigeration [9]. Compressor control is based on two or more units of the refrigeration system. During the operation of three compressor units, it is enough to change the power of one compressor, and 
the others compressors will work in the start-up/stop mode for ensuring smoothness of operation of a refrigeration plant. It is proposed to put the first compressor more powerful than the others, together with installation of the AKD 102 frequency converter. It is also proposed to use the frequency converters to control fans of air capacitors and it will allow saving some energy. As a result, the economy of the electric power on an auxiliary power station will make $20 \%$ of a refrigerator set [9].

The presented method of increasing the efficiency of a refrigerator set is economic with its small energy consumptions; however, the application in ship's refrigerator sets is rather difficult. Firstly, not all plants are supplied with three compressor units. The re-equipment costs larger expenses, and not every refrigeration system will be efficient due to factory design. One more problem connected to pipe-bend of warmth into outboard water: during the regulation of the compressor unit with the power parameters, the pipe-bend of warmth into outboard water is invariable. Modern ship refrigerators require an increase in power for quality freezing of the product. The temperature schedules not always correspond to actual conditions. This type of the frequency regulator can be applied only to some small industrial refrigerating machines at the factory, because the number of factors for ship's conditions is not considered [11-16].

In work [10], the method of digital control of piston compressors is described. The digital control is implemented by the controllable solenoid valve, which is installed on a cover of the block of compressor cylinders to operate the gas current coming to the area of absorption of a valve board (Figure 4).

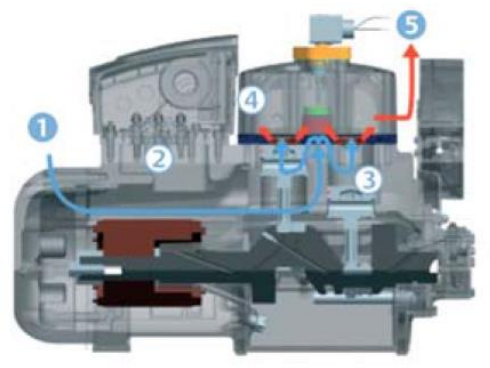

loading operation

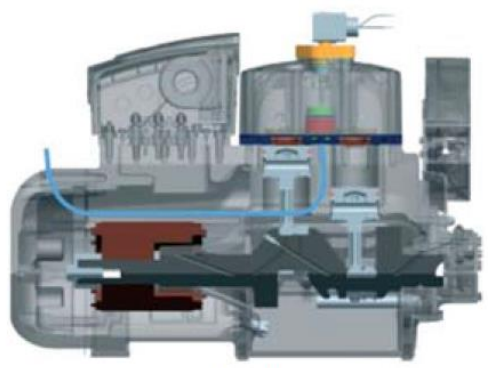

on load

1 coolant gets into the compressor

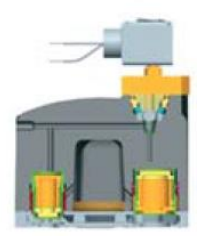

2 passes through the chamber

3 into valve board (in a state of no load operation the flow of coolant is blocked by pistol mechanism)

4 is contracted with pistons (load operation)

5 exits out of compressor (load operation)

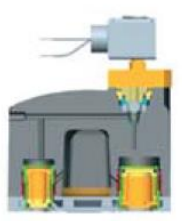

Fig. 4. Principle of digital regulation of refrigerating capacity of compressors: a) condition of loading at the left; b) condition of no-load operation on the right.

Using the method of digital control, it is possible to regulate refrigerating capacity of the piston compressor, but only when monitoring time of the actual compression of refrigerant.

\section{Conclusions}

The presented main methods for improving energy efficiency when operating refrigerators using various refrigerants have limited application. The increasing of energy efficiency of the ship can be achieved by various ways during the work of refrigeration system; one of 
such ways is decrease in energy consumption of refrigeration system. It can be achieved by the balanced operation of the compressor unit: the amplitude of starts and stops, the subcooling of refrigerant: greater cooling capacity and, accordingly, lower costs for pumping refrigerant. Having carried out the analysis of methods that, in turn, influence energy efficiency, it is possible to note the strong and the weak sides. In this analysis, a number of constructive features that should be considered at further development were revealed. With regard to improving the efficiency of the refrigeration system, it is necessary to introduce an adjustment system, since installation responsibilities are constantly changing, and monotonous work without any adjustments is not very effective. With the further development of the proposed methods, it is necessary to consider the experimental value for correct work of system as a whole.

Despite a number of factors that are not considered, the presented methods are promising and need further development and expansion of applicability in modern ship cooling technology.

\section{References}

1. A.G. Ionov, Production efficiency of cold (Publishing house, Kaliningrad, 1998)

2. G.G. Lalayev, Ship refrigerator sets and air conditioning systems (Transport, Moscow, 1981)

3. N.V. Lyubimov, Yu.N. Slastikhin, N.M. Ivanova, Increase in effectiveness of performance of a refrigerator set due to refrigerant overcooling, KGTU News, $41-46$ (2011)

4. G.M. Shvetsov, N.V Ladin, Ship refrigerator sets. The textbook for higher educational establishments (Transport, Moscow, 1986)

5. V.M. Mizin, D.V. Bolshakov, Increase in effectiveness of refrigerators by improvement of traditional types of devices, NIU ITMO, 30 - 37 (2014)

6. Federal law No. 7 Federal Law "About Environmental Protection" (2002)

7. Federal law from November 4, No. 128 Federal Law "About Ratification of the Kyoto Report to the UN Framework Convention on Climate Change" (2004)

8. M.Y. Katrayev, Increase in effectiveness of performance of a refrigerator set. Choice of a control algorithm of the electronic temperature-controlled valve, Refrigerating technique 4 (2011)

9. M.Y. Katrayev, Ways of increase in operation of refrigerating appliances, Complex use of the frequency converters (Making modern living possible)

10. A. Froman, M. Talyzin, S. Gorokhov, Digital regulation of efficiency of piston compressors of "STREAM", Refrigerating technique, 34 - 36 (2013)

11. V. Budnik, S. Chernyi, Procedia Engineering 150, 2150-2156 (2016)

12. S. Sokolov, A. Zhilenkov, S. Chernyi and A. Nyrkov, Procedia Computer Science 125, 420-426 (2018)

13. A. Nyrkov, A. Zhilenkov, S. Sokolov, S. Chernyi, Automation and Remote Control 791, 195-202 (2018)

14. A. Zhilenkov, S. Chernyi, Procedia Engineering 100,1247-1252 (2015)

15. S. Sokolov, A. Zhilenkov, A. Nyrkov, S. Chernyi, Advances in Intelligent Systems and Computing, 421-427 (2017)

16. S. Chernyi, A. Zhilenkov, S. Sokolov, A. Nyrkov, Vibroengineering PROCEDIA 13, 261-265 (2017) 